\title{
A Neurological Explanation of Strategic Mortgage Default
}

\author{
Michael J. Seiler • Eric Walden
}

Published online: 31 July 2014

(C) Springer Science+Business Media New York 2014

\begin{abstract}
This study examines strategic mortgage default on a neurological level. Specifically, we test two mainstream behavioral finance/economic theories: sunk cost fallacy and cognitive dissonance. Using fMRI technology, we identify a number of substrates within the brain that provide a neurobiological explanation for why some homeowners exercise their mortgage put option while others do not. We find that borrowers rationally do not suffer from the sunk cost fallacy as it relates to strategic default in that they significantly prioritize their negative equity position over the amount of their initial down payment. We do, however, find neurological support that cognitive dissonance is relevant in homeowners' thought processes as they toil with the hesitancy brought on by the believe that strategic default is immoral against the strong financial incentive to walk away from a substantially underwater mortgage.
\end{abstract}

Keywords Neurological real estate $\cdot$ Forensic real estate $\cdot \mathrm{fMRI} \cdot$ Strategic mortgage default

JEL Classification $\mathrm{C} 91 \cdot \mathrm{D} 81 \cdot \mathrm{G} 02 \cdot \mathrm{R} 39$

\section{Introduction}

The financial crisis began as a housing boom artificially created by a myopic financial system that encouraged and economically enabled homeowners across the country to qualify for mortgages they could not afford. Homeowners were more than willing to do

\section{J. Seiler ( $\square)$}

K. Dane Brooksher Endowed Chair Professor of Real Estate and Finance, The College of William \& Mary Mason School of Business Department of Finance, P.O. Box 8795, Williamsburg, VA 23187-8795, USA

e-mail: Michael.Seiler@mason.wm.edu

E. Walden

James C. Wetherbe Professor of Information Systems and Quantitative Sciences, Texas Tech University, Lubbock, TX 79409, USA

e-mail: Eric.Walden@ttu.edu 
or say just about anything to get into one, if not more than one, property. Now, during the current financial correction, some homeowners are willing to do just about anything to get out from under those same houses. One such course of action that has been welldocumented is the exercising of the homeowner's put option on the home (Guiso, Sapienza, and Zingales, 2013). Less formally, the decision to stop paying one's mortgage even though the homeowner has the financial ability to continue making payments is called "strategic mortgage default". "Homeowners who focus on the investment aspect of ownership no longer want to own an asset that has a negative monthly cash flow. ${ }^{2}$ Moreover, in non-recourse states, lenders are unable to pursue deficiency judgments against homeowners who default on a mortgage. ${ }^{3}$ As a result, many homeowners have decided to stop paying their mortgage and expose themselves to the extremely uncertain environment that awaits them on the other side of this decision. ${ }^{4}$ Among the greatest reasons not to default, even if one believes it is financially advisable, is the moral objection almost all homeowners have to breaching a legal contract (Guiso, Sapienza, and Zingales, 2013; and Wilkinson-Ryan and Hoffman, 2010). ${ }^{5}$

Strategic mortgage default is a high-stakes game for policymakers, lenders, and homeowners alike. For homeowners, the stakes go beyond the financial as the default process can be very emotionally taxing as well (White, 2010). To date, studies have identified various loan characteristics (purchase price, down payment, loan type, outstanding loan balance, and equity position) that influence the decision to strategically default (FICO, 2011). The current consensus is that a substantial amount of negative equity is necessary to trigger the decision (Bhutta, Dokko, and Shan, 2010). Guiso, Sapienza, and Zingales (2013) and Seiler et al. (2012) go beyond the economic triggers of default and examine the behavioral considerations. The purpose of the current investigation is to go even deeper and understand both the economic and behavioral motivations for strategic mortgage default at a neurological level. Specifically, what neurological substrates (areas in the brain) are associated with the various aspects of the decision to strategically default on a mortgage?

Through our ceteris paribus experimental design, we are able to dissect and differentiate between the importance of down payment, outstanding loan balance, and negative equity position. We find that homeowners avoid the sunk cost fallacy and rationally focus more economically on their (negative) equity position.

When examining scenarios where homeowners are extremely underwater, we find differential activation in both the anterior cingulate cortex and the motor cortex, two

\footnotetext{
$\overline{1}$ The inability to pay one's mortgage due to such factors as job loss, income curtailment, or prolonged illness is known as an "economic default."

${ }^{2}$ The negative monthly cash flow refers to the ability to rent a comparable home for less than what it costs to own the same home.

${ }^{3}$ Even in recourse states (there are 41 of them), legal maneuvers can make it unpalatable for lenders to come after defaulting underwater homeowners.

${ }^{4}$ The way in which the foreclosure process is being handled is constantly evolving across the country so much so that attorneys who specialize in helping homeowners navigate the process are often unsure of how to coach their clients through the maze of legal uncertainty.

${ }^{5}$ Seiler et al. (2012) document that additional disadvantages to defaulting include a reduced credit score making future credit both more difficult and more expensive to obtain, potential moving costs (if the home is a primary residence), uncertainly surrounding the tax treatment of waived deficiency judgments, and the social stigma of friends and family learning that the homeowner defaulted on a loan.
} 
substrates associated with feelings of cognitive dissonance. Thus, being so far underwater on a mortgage forces the homeowner to confront the financial incentive to strategically default even though the homeowner has a moral objection to the action (Veen et al. 2009). In comparison with trials where subjects indicated a lesser willingness to strategically default versus those trials in which a subject indicated a greater willingness to default, we find significantly greater activation in their left lingual gyrus an area of the brain associated with autobiographical self-reflection. In sum, we use fMRI technology to test existing behavioral economic theories to gain a deeper understanding of the emotional and behavioral aspects of the decision to strategically default.

\section{Literature Review}

On September 13, 1848, Phineas Gage, a railroad foreman working on the Rutland and Burlington railway in Vermont, suffered a severe and permanent brain injury when a tamping rod was propelled through the frontal cortex of his brain during an accidental explosion. ${ }^{6}$ While Gage was able to make a remarkable physical recovery from the accident, co-workers said his personality was so greatly altered that they no longer recognized their friend. His immediate and permanent personality change is acknowledged by most in the field as the beginning of forensic neurology. Since then, scientists have been able to associate various brain damage locations to corresponding mental capability losses. As a result, it has become clear that certain parts of the brain are responsible for carrying out very specific activities.

Functional Magnetic Resonance Imaging (fMRI) is the most widely used neurological tool in the field today to correlate these specific activities with various substrates within the brain (Huesing, Jancke, and Tag, 2006). Reasons for fMRI's widespread acceptance and use include its non-invasive process, high signal fidelity, outstanding spatial resolution, as well as its consistency and reproducibility (Belliveau et al. 1991). An fMRI scanner is able to measure specific changes in blood flow from one part of the brain to another by using the blood's magnetic properties (Ogawa et al. 1990; 1992). Logothetis et al. (2001) explain that the fMRI scanner tracks Blood Oxygen LevelDependent (BOLD) flows that signal increases in neurological activity in a localized part of the brain. Over time, this measured hemodynamic response has been used to correlate activation in different parts of the brain with very specific tasks performed by the subject. The result is an ability to understand various constructs without having to rely on participant self-reports. Moreover, fMRI studies are particularly relevant when attempting to understand processes that occur on a subconscious level (e.g., financial herding behavior), or any other process where hidden emotions are not easily accessed through introspection (e.g., strategic mortgage default). Ideally, fMRI data would be used in concert with traditional empirical methods to understand complex decisionmaking processes such as the ones studied in the current investigation.

FMRI scanners have only been used in a handful of financial studies. For example, Bruguier, Quartz, and Bossaerts (2010) use an fMRI to confirm that uninformed traders

\footnotetext{
${ }^{6}$ The tamping rod landed 30 yards away. It measured 3 feet, 8 in. in length and 1.25 in. in diameter. The rod (and Phineas' skull) is currently on display at the Warren Anatomical Museum at Harvard University's School of Medicine.
} 
can infer relevant financial information merely from observing the trading outcomes of informed insiders. Their study was experimentally based and used 20 Caltech students as their sample participants. Preuschoff, Quartz, and Bossaerts (2008) employed 19 subjects during their fMRI investigation of whether and how the brain can accomplish risk prediction during a gambling experiment. The authors found that a part of the brain known as the insula is a significant correlate with risk prediction error. Gambling was also the focus in a study by $\mathrm{Wu}$, Bossaerts, and Knutson (2011) who examined the impact of financial skewness on risk taking. Whereas the Markowitz (1952) MPT model conveniently assumes returns are normally distributed, the authors find that this assumption overlooks the reality that investors do incorporate expected return skewness into their selection preferences. Specifically, skewed gambles are associated with greater activity in the anterior insula than gambles with symmetric future potential outcomes.

Fryman et al. (2014) use fMRI technology to delve deeper into existing behavioral theories such as the Barberis and Xiong (2012) Realization Utility hypothesis which maintains that the disposition effect is explained by the fact that investors derive utility directly from the immediate realizations of gains and losses. The authors argue that field data which has been used in the past (Barber and Odean, 2000; Grinblatt and Keloharju, 2009; and Choi et al. 2009) does not offer the same level of control as an experimental design. As a result, teasing out specific components of a theory to truly differentiate one theory from another is not always possible with field data.

Brennan and Lo (2011) provide an evolutionary explanation for why researchers have been unable thus far to create a unified theory to explain what appears to be successful, yet irrational behavior by not only humans, but a number of different organisms over time. The authors mathematically describe that it is in fact necessary for the survival of the species for some portion of the population to engage in excessive risk-taking that may appear sub-optimal at the individual level, but completely rational and optimal for society as a whole. In fact, Brennan and Lo (2011) argue that it is the diversification in behavior that ensures the survival of the species, even though many of the individual irrational behaviors all but disallow the survival of the single entity engaging in such behavior. In sum, researchers are only beginning to scratch the surface on how neurological finance technology might be employed to better understand a wide spectrum of disjointed behavioral economic theories and someday arrive at a single unified theory to explain "rational" behavior. This paper makes an intentional step in this direction.

\section{Testable Behavioral Theories}

In this study we directly test the behavioral finance/economic theories of sunk cost fallacy and cognitive dissonance as they relate to strategic mortgage default behavior. A "sunk cost" is one that has already been expended and cannot be recovered no matter what action is taken moving forward (Staw, 1976). ${ }^{7}$ As such, a sunk cost should rationally be ignored when making decisions in the present. Still, it is well documented

\footnotetext{
${ }^{7}$ At the time of Staw (1976), the more common term was "escalation of commitment." It has subsequently been referred to more often in a business environment as "sunk cost fallacy." In game theory, consideration of sunk costs are often referred to the "Concorde Effect," named after the observed behavior of the British and French governments' continued investment in the Concorde airplane long after it was evident the economics clearly did not support further production efforts.
} 
that people bring in sunk costs to their current decision-making processes. ${ }^{8}$ Doing so is said to reflect a "sunk cost fallacy." Behaviorally, we test for the sunk costs fallacy by comparing whether homeowners focus more on their original down payment made on the house (a sunk cost) versus their current (more relevant) negative equity position. Neurologically, we test for the sunk cost fallacy by looking for significantly differential activation in the lateral and parietal cortexes (Zeng et al. 2013).

Our second testable theory is cognitive dissonance, the feeling we experience when our planned actions are incongruent with our internal belief system. This discrepancy can cause a great amount of anguish because we are internally debating doing what we want to do when we know that what we want to do does not measure up to our moral code of conduct. As it relates to strategic mortgage default, homeowners who are extremely underwater want to walk away from their financial obligations, but do not feel right about it because they have a moral opposition to strategic default. ${ }^{9}$ Veen et al. (2009) conclude that significant activation in the anterior cingulated cortex is associated with cognitive dissonance. As such, we directly test for cognitive dissonance using the fMRI areas of activation.

\section{Sample}

Participants in our study include 20 homeowners (each with an existing mortgage) from a mid-sized southwestern city. The average age of our participants is 44.9 years, while the average age of homeowners reported in the American Housing Survey (AHS) and American Community Survey (ACS) is 52. Our (AHS) participants are $62.5 \%$ $(79.1 \%)$ Caucasian, and $60 \%(52.3 \%)$ are married with $55 \%(66.2 \%)$ having at least one child. Finally, $50 \%$ of our sample participants hold a college degree, whereas the national average is $33.8 \%$ of homeowners. In sum, it appears our sample is reasonably reflective of the overall homeowner profile across the U.S. ${ }^{10}$

\section{Experimental Design}

Advertisements to participate in our study were placed in the local newspaper, ${ }^{11}$ and subjects were paid $\$ 25$ for their participation. ${ }^{12}$ Subjects were not told about the specific focus of the research. They were simply told we were conducting a study of the

\footnotetext{
${ }^{8}$ While a bit of a hard sell, authors such as Baliga and Ely (2011) argue that due to an array of possible alternative mental constraints, considering sunk costs can be partially justified. In this study, we adopt a more traditional approach of viewing the incorporation of sunk costs as a fallacy.

${ }^{9}$ Several studies have documented the moral desire to avoid any type of breach of contract as well as the real estate specific immorality of hurting their neighbors through a foreclosure contagion, or spillover, effect.

${ }^{10}$ To the extent tests are possible, demographic characteristics do not appear to impact our results.

${ }^{11}$ We selected participants on a first come basis until our desired sample size of 20 was met.

12 Baker and Chinloy (2012) discuss that compensation need only be based on performance in tasks where choices are strictly economic. Alternatively, in a strategic mortgage default setting, paying participants based on performance makes no sense because considerations surrounding this decision go beyond purely economic factors to include a number of well-documented behavioral inputs. Moreover, the outcome of such decisions varies greatly from one person to another and may not be felt for many years to come. For all these reasons, we compensate participants using a flat fee.
} 
residential real estate market. Upon their arrival, the participants were described the task they were to perform and asked if they had any questions before entering the fMRI scanner.

The experimental task required subjects to read loan characteristics associated with a hypothetical mortgage and answer how likely he or she is to strategically default on such a mortgage under different financial conditions. Strategic mortgage default likelihood was presented on a 9-point scale ranging from highly likely (1) to highly unlikely (9) to default. It was explained to subjects that strategic default meant that they could afford the monthly payments, but still choose to default. In each trial, subjects were given the following pieces of financial information: Purchase price, down payment amount, current market price, remaining loan balance, and equity position. ${ }^{13}$ Panels A through D of Table 1 report the 36 semi-randomly presented scenarios used in the study necessary to isolate the effects of negative equity, down payment, and outstanding loan balance. ${ }^{14}$ Panel E shares a screen capture of the information provided to the subjects for a representative trial of the experiment.

The subjects were given 14 seconds to answer each question. ${ }^{15}$ The answer screen was followed by a fixation cross that lasted two seconds before another trial was given. The question answering took a total of 9 min and 36 seconds. In addition, before the questions, high-resolution scans of the subject's brain were taken to measure the unique characteristics of each participant's brain chemistry. This pre-screening took approximately five minutes.

\section{Methodology}

The functional imaging was conducted using a Siemens 3.0 Tesla Skyra to acquire gradient echo T2*-weighted echoplaner images (EPI) with Blood Oxygenation LevelDependent (BOLD) contrast. Each volume was acquired in an interleaved manner. The imaging parameters were as follows, echo time: $20 \mathrm{~ms}$; field of view: $240 \mathrm{~mm}$; flip angle: 80; in-plane resolution and slice thickness: $3.5 \mathrm{~mm}$; repetition time: 2,000 $\mathrm{ms}$. Whole brain high-resolution structural scans $(1 \times 1 \times 1 \mathrm{~mm})$ were acquired from all subjects. Images were then motion corrected with MCFLIRT (Jenkinson et al. 2002) and spatially smoothed using a Gaussian kernel with a width of $5 \mathrm{~mm}$. High pass temporal filtering (using a filter width of 100 seconds) was also applied to the data. Each T2 (functional) brain volume consists of approximately 40,000 voxels ( $3 \mathrm{~mm} *$ $3 \mathrm{~mm} * 3.5 \mathrm{~mm}$ boxes) of brain. The full brain was measured once every two seconds

\footnotetext{
${ }^{13}$ Because being underwater is a necessary condition for strategic mortgage default, all of our scenarios are associated with negative equity. As such, the behavioral theories we test are all taking place in the loss domain as defined in Kahneman and Tversky (1979).

${ }^{14}$ Note that by pairing the scenarios the way we did allows us to conduct a ceteris paribus analysis so that we can attribute and difference in results to the sole variable that differs in the analysis.

${ }^{15}$ This interval was deemed appropriate through pre-testing in that it allows sufficient time for blood to flow to the specific area (s) of the brain while contemplating the decision, but not so much time that the respondent's mind begins to drift. It should be noted that if a sub-optimal interval is selected, it would work towards a null result. It is also worthy of noting the limitation of any fMRI study in that the reaction observed is an initial reaction and may or may not be different over time. This is especially important to note given that the strategic default process is typically lengthy.
} 
Table 1 Home characteristic scenarios. This table reports the 36 scenarios presented in various orders and combinations to participants. Panel A pairs scenarios by lower priced homes with the same amount of negative equity. Panel B pairs scenarios by lower priced homes with the same price decline. Panel C pairs scenarios by higher priced homes with the same amount of negative equity. Panel D pairs scenarios by higher priced homes with the same price decline. Panel E shares a sample screenshot of what the participant sees during one of the trials

\begin{tabular}{|c|c|c|c|c|c|}
\hline Scenario & $\begin{array}{c}\text { Purchase } \\
\text { Price }\end{array}$ & $\begin{array}{c}\text { Down } \\
\text { Payment }\end{array}$ & $\begin{array}{c}\text { Loan } \\
\text { Balance }\end{array}$ & $\begin{array}{c}\text { Current } \\
\text { Price }\end{array}$ & $\begin{array}{c}\text { Equity } \\
\text { Position }\end{array}$ \\
\hline \multicolumn{6}{|c|}{ Panel A: Lower Priced Homes with Paired Negative Equity Scenarios } \\
\hline 1 & 80,000 & 25,000 & 50,000 & 40,000 & $(10,000)$ \\
\hline 2 & 60,000 & 5,000 & 50,000 & 40,000 & $(10,000)$ \\
\hline 3 & 85,000 & 30,000 & 50,000 & 35,000 & $(15,000)$ \\
\hline 4 & 65,000 & 10,000 & 50,000 & 35,000 & $(15,000)$ \\
\hline 5 & 110,000 & 25,000 & 80,000 & 60,000 & $(20,000)$ \\
\hline 6 & 95,000 & 10,000 & 80,000 & 60,000 & $(20,000)$ \\
\hline 7 & 90,000 & 30,000 & 55,000 & 30,000 & $(25,000)$ \\
\hline 8 & 70,000 & 10,000 & 55,000 & 30,000 & $(25,000)$ \\
\hline 9 & 125,000 & 35,000 & 85,000 & 55,000 & $(30,000)$ \\
\hline 10 & 105,000 & 15,000 & 85,000 & 55,000 & $(30,000)$ \\
\hline \multicolumn{6}{|c|}{ Panel B: Lower Priced Homes with Paired Price Decline Scenarios } \\
\hline 11 & 70,000 & 5,000 & 60,000 & 30,000 & $(30,000)$ \\
\hline 12 & 70,000 & 25,000 & 40,000 & 30,000 & $(10,000)$ \\
\hline 13 & 80,000 & 5,000 & 70,000 & 50,000 & $(20,000)$ \\
\hline 14 & 80,000 & 15,000 & 60,000 & 50,000 & $(10,000)$ \\
\hline 15 & 100,000 & 10,000 & 85,000 & 55,000 & $(30,000)$ \\
\hline 16 & 100,000 & 25,000 & 70,000 & 55,000 & $(15,000)$ \\
\hline 17 & 120,000 & 20,000 & 95,000 & 70,000 & $(25,000)$ \\
\hline 18 & 120,000 & 30,000 & 85,000 & 70,000 & $(15,000)$ \\
\hline \multicolumn{6}{|c|}{ Panel C: Higher Priced Homes with Paired Negative Equity Scenarios } \\
\hline 19 & 245,000 & 65,000 & 170,000 & 70,000 & $(100,000)$ \\
\hline 20 & 180,000 & 15,000 & 155,000 & 55,000 & $(100,000)$ \\
\hline 21 & 230,000 & 30,000 & 190,000 & 55,000 & $(135,000)$ \\
\hline 22 & 205,000 & 10,000 & 185,000 & 50,000 & $(135,000)$ \\
\hline 23 & 290,000 & 50,000 & 230,000 & 60,000 & $(170,000)$ \\
\hline 24 & 255,000 & 15,000 & 230,000 & 60,000 & $(170,000)$ \\
\hline 25 & 365,000 & 75,000 & 280,000 & 80,000 & $(200,000)$ \\
\hline 26 & 310,000 & 20,000 & 280,000 & 80,000 & $(200,000)$ \\
\hline \multicolumn{6}{|c|}{ Panel D: Higher Priced Homes with Paired Price Decline Scenarios } \\
\hline 27 & 235,000 & 10,000 & 215,000 & 65,000 & $(150,000)$ \\
\hline 28 & 235,000 & 60,000 & 165,000 & 65,000 & $(100,000)$ \\
\hline 29 & 280,000 & 15,000 & 255,000 & 70,000 & $(185,000)$ \\
\hline 30 & 280,000 & 70,000 & 200,000 & 70,000 & $(130,000)$ \\
\hline 31 & 305,000 & 10,000 & 285,000 & 85,000 & $(200,000)$ \\
\hline 32 & 305,000 & 95,000 & 200,000 & 85,000 & $(115,000)$ \\
\hline 33 & 295,000 & 25,000 & 260,000 & 95,000 & $(165,000)$ \\
\hline 34 & 295,000 & 65,000 & 220,000 & 95,000 & $(125,000)$ \\
\hline 35 & 265,000 & 35,000 & 220,000 & 75,000 & $(145,000)$ \\
\hline 36 & 265,000 & 80,000 & 175,000 & 75,000 & $(100,000)$ \\
\hline
\end{tabular}

Panel E: Sample Screen Capture of what was Shown to the Participant

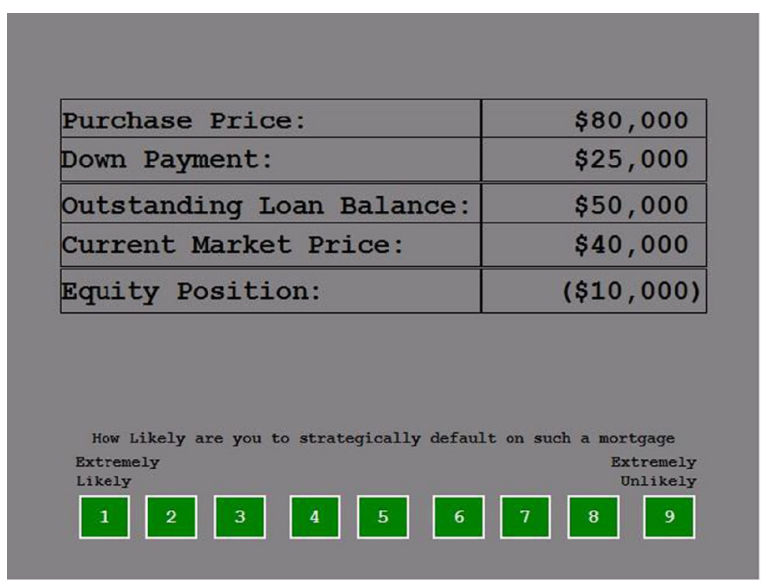


for 482 full brain volumes per subject, approximately 20 million data points per subject, and nearly half a billion data points for the entire analysis.

The first step in the analysis was to create a linear model of the form $Y_{t}=X_{t} \beta+\varepsilon_{t}$ for each voxel across time, where $Y_{t}$ is the level of activation observed in a voxel at a specific time, and $X_{t}$ is a matrix of dummy variables that is non-zero during the presentation of the stimuli, and $\beta$ is a vector to be estimated. The $X$ variable takes the form of a gamma function because the hemodynamic response function (HRF) is known to follow a similar pattern. In other words, after a stimulus, it takes some time for the blood to flow to an area to replenish the blood used by the neurons. Using a gamma function for $\mathrm{X}$ allows us to weight the activation more heavily when we expect the blood to actually flow in response to the stimulus. The data was pre-whitened using FSL's FILM to correct for autocorrelation (Woolrich et al. 2001). To standardize the $\beta \mathrm{s}$, we divide by the standard error to create a t-statistic. This is further standardized into a normalized z-statistic to make results comparable across different degrees of freedom.

After doing the above, we have a set of maps of the brain for the subject, for each $\beta$, with each voxel expressed as a z-statistic, representing the probability that a particular voxel has unusual activation during the stimuli. We have one full brain map per stimulus. We then subtract these maps to see where one stimulus (i.e., the z-score for a particular $\beta$ ) is greater than another stimulus. For example, we may subtract the activation maps for trials where houses are severely underwater from the maps where houses are slightly underwater. This results in a measure of relative activation so that we may see where stimulus one is greater than stimulus two. It is important to be mindful that all results, therefore, are relative.

Each subject's functional scans are then registered to the subject's high resolution scan. A solid body transformation, which allows movement in three dimensions (up/ down, left/right, forward/backward) plus three rotational dimensions, is calculated. The high resolution image is then registered to a standard image - the Montreal Neurological Institute (MNI) standardized brain template. This is because each person's brain, like each person's body, is slightly different in shape. This transformation is accomplished using FNIRT (Andersson, Jenkinson, and Smith 2007), a non-linear registration. This allows for movement in the six directions, plus expansion or contraction along each axis, plus skews, plus local abnormalities.

The z-statistics maps from each subject are then converted through the two transformations so each subject's map is the same shape, ensuring that each voxel corresponds to the same brain region. For each voxel in standard space, we create a model of the form $Y_{k t}=X_{k t} \beta+\eta_{k t}$, where $k$ indexes a specific subject, and $\eta_{k t}=\delta_{k}+\varepsilon_{k t}$, where $\delta_{k}$ is the error term for an individual, and $\varepsilon_{\mathrm{kt}}$ is the error term for a specific time for an individual. In other words, we create a random effects model where individuals are drawn from a population with a particular distribution. This is done using a Bayesian tool called FSL's FLAME (Woolrich et al. 2004).

We now have a standardized map of relative activations across all subjects corrected for both individual and trial-by-trial variance. This map is made up of tens of thousands of z-scores, so we face a multiple comparisons problem. We expect to find hundreds of voxels of activation that are type I errors - voxels that show significant activation just by random chance. To correct for this, we first remove all z-scores less than 1.96 to arrive at only highly significant voxels of activation, and then we look for contiguous clusters. Using random field theory, we calculate the probability of a cluster of that size 
appearing randomly (Worsley, 2001). This works well because single voxels are excluded and only larger volumes of activation appear. To report results, we show a picture of the standardized brain with significant voxels shown by color. Red corresponds to a voxel with a z-score of 1.96 and yellow to a z-score of 5.

\section{Experimental Results}

Guiso, Sapienza, and Zingales (2013) and Seiler et al. (2012) convincingly demonstrate that having negative equity is a necessary condition to strategically default on one's mortgage. Moreover, the greater the amount by which the homeowner is underwater, the greater the incentive (and likelihood) to default. Our constructed negative equity scenarios were specifically designed to measure the relation between likelihood of strategic mortgage default and degree of negative equity. Panel A of Table 2 reports a pair-wise analysis where the home declines in price by the exact same amount, but the degree of being underwater changes. Ceteris paribus, scenarios associated with greater negative equity are significantly more likely to be defaulted on than homes with less negative equity. Panels B and C of Table 2 perform the same analysis except this time, the scenarios are separated by high priced homes (Panel B) versus lower priced homes (Panel C). Consistent with the extant literature, homeowners are significantly more

Table 2 Willingness to strategically default and degree of negative equity. This table reports differences in stated willingness to strategically default on one's mortgage at various levels of negative equity (while holding constant purchase price and current price of the home). Panel A contains the full sample of paired scenarios, while Panels B and C report sub-sample results for high and low priced homes, respectively

\begin{tabular}{|c|c|c|c|}
\hline & Sample size & Mean willingness to strategically default & $p$-value \\
\hline \multicolumn{4}{|c|}{ Panel A: Scenarios with the same decline in price, but different levels of negative equity } \\
\hline $\begin{array}{l}\text { More Negative Equity } \\
\text { (Scenarios } 11,13,15,17,27\end{array}$ & $\begin{array}{l}178 \\
7,29,31,33,35)\end{array}$ & 5.22 & $0.002 * * *$ \\
\hline $\begin{array}{l}\text { Less Negative Equity } \\
\quad \text { (Scenarios } 12,14,16,18,28\end{array}$ & $\begin{array}{l}177 \\
8,30,32,34,36)\end{array}$ & 6.13 & \\
\hline \multicolumn{4}{|c|}{ Panel B: Higher Priced Home Scenarios with the same decline in price, but different levels of negative equity } \\
\hline $\begin{array}{l}\text { More Negative Equity } \\
\text { (Scenarios 27,29,31,33,35 }\end{array}$ & 5) & 3.95 & $0.001 * * *$ \\
\hline $\begin{array}{l}\text { Less Negative Equity } \\
\quad \text { (Scenarios } 28,30,32,34,36\end{array}$ & 6) & 5.22 & \\
\hline \multicolumn{4}{|c|}{ Panel C: Lower Priced Home Scenarios with the same decline in price, but different levels of negative equity } \\
\hline $\begin{array}{l}\text { More Negative Equity } \\
\qquad(\text { Scenarios } 11,13,15,17)\end{array}$ & 80 & 6.79 & 0.176 \\
\hline $\begin{array}{l}\text { Less Negative Equity } \\
\qquad(\text { Scenarios } 12,14,16,18)\end{array}$ & 78 & 7.28 & \\
\hline
\end{tabular}

NOTES: * indicates statistical significance at the $10 \% ; * *$ indicates statistical significance at the $5 \%$; *** indicates statistical significance at the $1 \%$. Significance tests are based on Independent Samples T-tests after a Levene statistic was used to determine if the variances are heterogeneous 
likely to strategically default on higher priced homes, but not on lower priced homes (because the negative equity is greater (Table 3 )).

The sunk cost fallacy in behavioral finance refers to the inclination of individuals to irrationally consider a cost that was paid for an investment/asset (that can no longer be recovered) when making an investment choice about the future. In the current context, we examine a homeowner's relative intention to make his strategic default decision based on the down payment he made when purchasing the house (a sunk cost) versus his current negative equity position. Similar to the construction of the previous table, we specifically designed scenarios to isolate the differential effects of negative equity and down payment. Panel A splits the sample by greater versus lesser down payment amounts while holding negative equity constant. Rationally, there is not a significant difference between the scenarios where the homeowner put down a greater versus lesser down payment. This rational result continues to hold in Panels B and C when the trials are segmented by high versus low priced homes, respectively. As such, we do not find support for the sunk cost fallacy as it relates to strategic mortgage default.

In a multivariate examination of the relative impacts of negative equity versus down payment, Column (1) of Table 4 confirms our earlier finding of rationality that people care more about their current equity position than their past down payment. Because of the intentionally paired scenarios which isolate the effect of negative equity position

Table 3 Willingness to strategically default and down payment amount. This table reports differences in stated willingness to strategically default on one's mortgage at various levels of initial down payment while holding constant the negative equity position (through both loan balance and current price) in the home. Panel A contains the full sample of paired scenarios, while Panels B and C report sub-sample results for high and low priced homes, respectively

$$
\text { Sample size Mean willingness to strategically default } \quad p \text {-value }
$$

Panel A: Scenarios with the same negative equity position, but different down payment amounts
Greater Down Payment
179
5.77
0.889

(Scenarios 1,3,5,7,9,19,21,23,25)

Lesser Down Payment $\quad 178 \quad 5.72$

(Scenarios 2,4,6,8,10,20,22,24,26)

Panel B: Higher Priced Home Scenarios with the same negative equity position, but different down payment amounts

$\begin{array}{cccc}\text { Greater Down Payment } & 79 & 4.32 & 0.492 \\ \begin{array}{c}\text { (Scenarios 19,21,23,25) } \\ \text { Lesser Down Payment }\end{array} & 78 & 4.03\end{array}$

(Scenarios 20,22,24,26)

Panel C: Lower Priced Home Scenarios with the same negative equity position, but different down payment amounts

$\begin{array}{cccc}\text { Greater Down Payment } & 100 & 6.91 & 0.640 \\ \quad(\text { Scenarios } 1,3,5,7,9) & & 7.05 \\ \text { Lesser Down Payment } & 100 & \end{array}$

NOTES: * indicates statistical significance at the $10 \% ; * *$ indicates statistical significance at the $5 \%$; *** indicates statistical significance at the $1 \%$. Significance tests are based on Independent Samples T-tests after a Levene statistic was used to determine if the variances are heterogeneous 
Table 4 Relative influence of negative equity position, down payment and loan balance on willingness to strategically default. This table reports a series of regressions aimed at measuring the relative importance of three loan characteristics: Negative Equity Position, Down Payment and Loan Balance on the participant's stated willingness to strategically default on their loan. Because of the intentionally paired scenarios which isolate the effect of negative equity position and down payment, a high correlation was necessary between negative equity position and outstanding loan balance. As such, two separate regressions are estimated allowing for the systematic exclusion of each variable to avoid a multi-collinearity problem

(1)

$7.280 * * *$

Intercept

$2.024^{* * *}$

Equity Position

Down Payment

Outstanding Loan Balance $-1.705^{* * *}$

F-Statistic

$p$-value

Adjusted $\mathrm{R}^{2}$

$.000^{* * *}$

.237

Sample Size
$0.680^{*}$

(2)

$7.92^{* * *}$

(0.192)

$.000 * * *$

.230

712

NOTES: * indicates statistical significance at the $10 \%$;* indicates statistical significance at the $5 \%$; *** indicates statistical significance at the $1 \%$

and down payment, a high correlation was necessarily created within the scenarios between negative equity position and outstanding loan balance. As such, our second regression in Column (2) reflects a similar conclusion in terms of participant rationality. Specifically, people care more about their current outstanding loan balance than they do their past down payment which does not support sunk cost fallacy predictions.

\section{fMRI Results}

The preceding analysis is based on a traditional experimental design approach where the conclusions are drawn solely from what the respondent indicates he would do in each scenario. But since people do not always know why they do the things they do, we now turn to the major contribution of this study. Specifically, we next share the fMRI results for all participants while they consider the 36 underwater scenarios and determine their willingness to strategically default.

\section{Sunk Cost Fallacy}

As previously discussed, we follow Zeng et al. (2013) in testing the sunk costs fallacy by examining potential areas of differential activation in the lateral and parietal cortexes. Consistent with our behavioral findings, there no statistically significant differences in brain activity between trials that compare down payment versus negative 
equity positions. As such, our neurological findings support our behavioral conclusions that homeowners do not fall prey to the sunk cost fallacy as it relates to strategic mortgage default.

\section{Negative Equity and Cognitive Dissonance}

Based on the extant literature and experimental results reported earlier in this study, it is generally accepted that being substantially underwater is a necessary condition for strategic mortgage default to occur. But, extreme negative equity is not a sufficient condition. For some, the moral objection to default outweighs the financial incentive to exercise one's put option. To better understand what goes on inside the brain of those who are willing to take this leap, we segment the sample into those who are versus those who are not willing to strategically default even though they are extremely underwater.

In behavioral finance, cognitive dissonance describes an uncomfortable psychological condition where our actions do not match our belief system. This inconsistent or

\section{A Areas of greater activation for Slightly over Severely Underwater Trials}
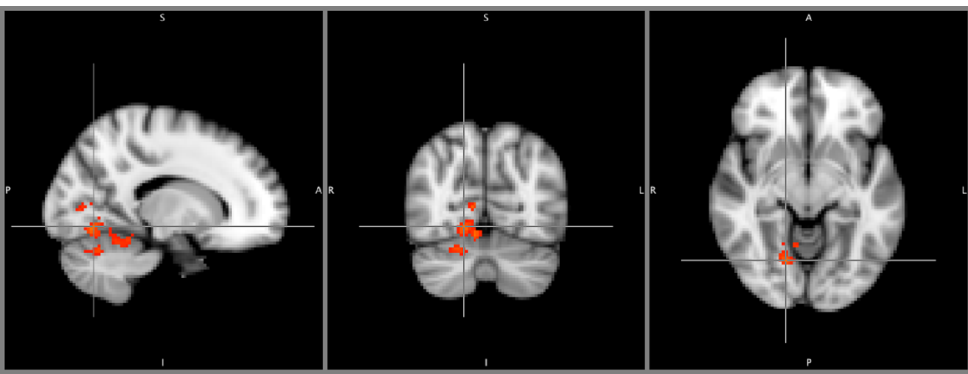

B Areas of greater activation for Severely over Slightly Underwater Trials
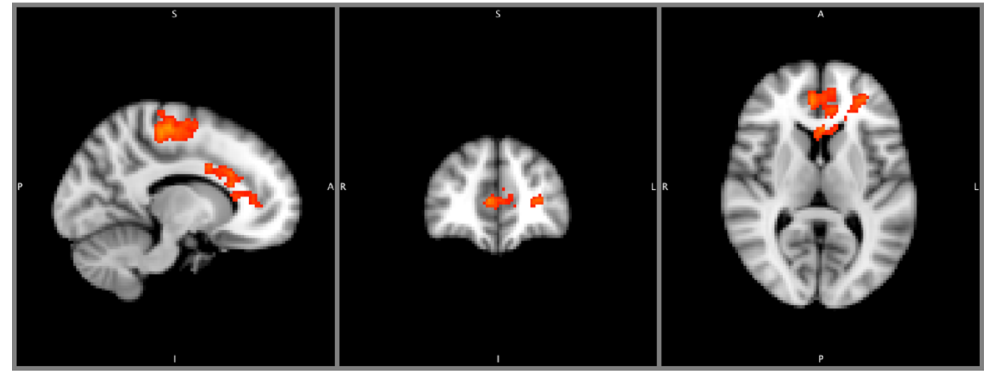

\begin{tabular}{|l|l|l|l|l|l|l|}
\hline & Voxels & $\begin{array}{c}\text { P-value of } \\
\text { cluster }\end{array}$ & Z-MAX & $\begin{array}{l}\text { Z-MAX } \\
\text { X (mm) }\end{array}$ & $\begin{array}{l}\text { Z-MAX } \\
\text { Y (mm) }\end{array}$ & $\begin{array}{l}\text { Z-MAX } \\
\text { Z (mm) }\end{array}$ \\
\hline $\begin{array}{l}\text { Slightly }> \\
\text { Severely }\end{array}$ & 656 & 0.00281 & 3.37 & 16 & -68 & -8 \\
\hline $\begin{array}{l}\text { Severely }> \\
\text { Slightly }\end{array}$ & 1425 & $2.21 \mathrm{e}-06$ & 3.78 & -10 & -28 & 56 \\
\hline $\begin{array}{l}\text { Severely }> \\
\text { Slightly }\end{array}$ & 942 & 0.000158 & 3.56 & 6 & 44 & 8 \\
\hline
\end{tabular}

Fig. 1 fMRI results when comparing severely underwater homeowners to slightly underwater homeowners 
A Areas of greater activation for those who are willing over those who are unwilling to default

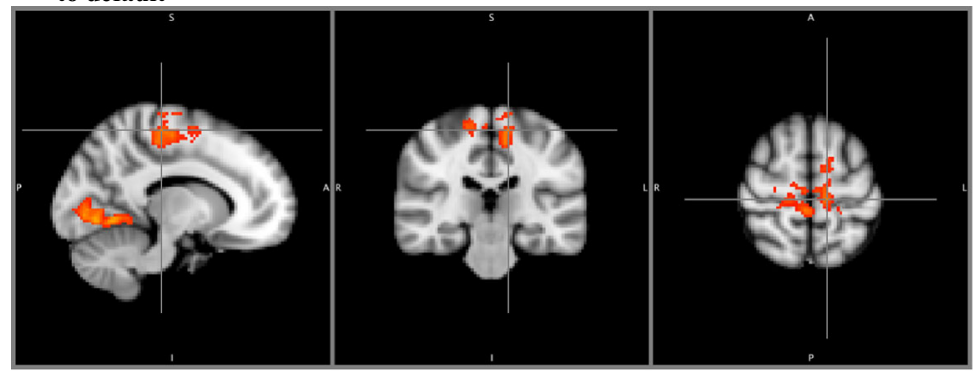

B Areas of greater activation for those who are unwilling over those who are willing to default

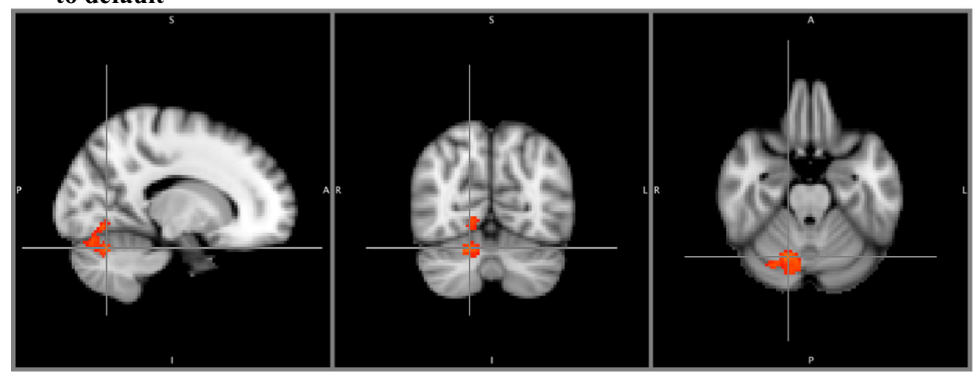

\begin{tabular}{|l|l|l|l|l|l|l|}
\hline & Voxels & $\begin{array}{c}\text { P-value of } \\
\text { cluster }\end{array}$ & Z-MAX & $\begin{array}{l}\text { Z-MAX } \\
\mathbf{X}(\mathbf{m m})\end{array}$ & $\begin{array}{l}\text { Z-MAX } \\
\text { Y (mm) }\end{array}$ & $\begin{array}{l}\text { Z-MAX Z } \\
(\mathbf{m m})\end{array}$ \\
\hline $\begin{array}{l}\text { Willing }> \\
\text { Unwilling }\end{array}$ & 826 & 0.000115 & 3.52 & -12 & -26 & 60 \\
\hline $\begin{array}{l}\text { Willing }> \\
\text { Unwilling }\end{array}$ & 675 & 0.000668 & 4.02 & -10 & -64 & -6 \\
\hline $\begin{array}{l}\text { Unwilling }> \\
\text { Willing }\end{array}$ & 351 & 0.0484 & 3.35 & 16 & -66 & -24 \\
\hline
\end{tabular}

Fig. 2 fMRI results when parsing the sample by trials in which subjects indicate a willingness to strategically default versus trials where they do not

dissonant feeling is so unpleasant that people often change either their belief system or their behavior in order to rid the brain of such an affect. We find in Fig. 1 that being substantially underwater causes statistically significant activation in the anterior cingulated cortex. Veen et al. (2009) conclude that this area of the brain is associated with cognitive dissonance. Our results reflect the discomfort people feel when they have a moral objection to strategic default and yet know that they are now being confronted with the financial incentive to do what they do not want to do Fig. 2.

As a robustness check to further test the cognitive dissonance hypothesis, we examine the trials where people claim they would default compared to trials where they would not default. ${ }^{16}$ On trials where homeowners indicated they would default, they show significantly more activation in the left lingual gyrus and motor cortex. These areas have been found to be activated when people engage in autobiographical thinking (James and O'Boyle, 2014). Thus, people who are willing to strategically

\footnotetext{
${ }^{16}$ Two people claimed they would never default under any condition, and as such, have been temporarily excluded from this portion of the analysis.
} 
default are truly imagining themselves in this difficult position, whereas those who are not willing to default imagine themselves in the same situation to a significantly lesser extent. Failing to default simply means following the status quo, ${ }^{17}$ and requires little contemplation of one's actions. Default, on the other hand, requires a great deal more consideration of action. ${ }^{18}$ This finding adds support for the finding that homeowners are truly engaged in an internal struggle as described in the theory of cognitive dissonance.

\section{Limitations}

When using a traditional regression-based analysis, researchers collect transactions data and then attempt to "hold all else constant" through the inclusion of an extensive list of independent variables. Alternatively, in an experiment, ceteris paribus is achieved through a proper research design, but then an assumption is made that what holds in the experiment translates into the real world. In this sense, traditional and experimental methods should be viewed as two different approaches to achieve the same goal. The traditional approach assumes the real world can be sufficiently represented by a few key independent variables, whereas an experimental approach assumes the real world can be sufficiently represented by controlling for a few key variables within the design. That said, one limitation of this study is whether or not what we find in the lab will hold in the real world.

\section{Conclusions}

We use experimental methods and fMRI technology to test two behavioral finance/ economic theories as they relate to strategic mortgage default. Behaviorally, we find that because homeowners' stated willingness to strategically default is significantly more explained by their current negative equity position as opposed to the size of their initial down payment, they do not suffer from the well-documented sunk cost fallacy. Neurologically, there is also insufficient evidence to support the sunk cost fallacy based on a lack of differential activation in the lateral and parietal cortex areas of the brain.

Continuing, when subjects are severely underwater, they show activity in the anterior cingulate cortex, an area known to be active when people experience cognitive dissonance, our second behavioral finance/economic theory tested. That is, being severely underwater creates a conflict between people's moral urge to honor contracts, and their financial urge to exit a poor investment. Moreover, subjects further underwater indicate they are more willing to strategically default on their mortgage, and engage several brain areas associated with self-reflection. This finding serves as a confirmatory robustness check to the cognitive dissonance conclusion.

Our sincere hope is that more studies in this area follow because until we learn why homeowners strategically default on their mortgage, policies aimed at curbing this

\footnotetext{
${ }^{17}$ Mortgage payments are typically automatically drafted from homeowners' banking accounts.

${ }^{18}$ In addition to initiating the stopping of automatic drafts, the homeowners will eventually have to move out as well.
} 
burgeoning trend will be randomly effective at best. Instead, a more thoughtful and insightful line of research can substantially help tailor efforts for policymakers moving forward.

\section{References}

Andersson, J.L., Jenkinson, M., \& Smith, S.M. (2007). Non-linear Registration, aka Spatial Normalisation. FMRIB technical report TR07JA2.

Baker, H. K., \& Chinloy, P. (2012). Real Estate: Markets and Investment Opportunities. New York: Oxford University Press.

Baliga, S., \& Ely, J. (2011). Mnemonomics: the sunk cost fallacy as a memory kludge. American Economic Journal: Microeconomics, 3(4), 35-67.

Barber, B. M., \& Odean, T. (2000). Trading is hazardous to your wealth: the common stock investment performance of individual investors. Journal of Finance, 55(2), 773-806.

Barberis, N., \& Xiong, W. (2012). Realization utility. Journal of Financial Economics, 104(2), 251-271.

Belliveau, J., Kennedy, D., McKinstry, R., Buchbinder, B., Weisskoff, R., Cohen, M., Vevea, J., Brady, T., \& Rosen, B. (1991). Functional mapping of the human visual cortex by magnetic resonance imaging. Science, 254(17), 716-719.

Bhutta, N., Dokko, J., \& Shan, H. (2010). The Depth of Negative Equity and Mortgage Default Decisions. Federal Reserve Board of Governors Finance and Economics Discussion Series, Working Paper 201035 .

Brennan, T. J., \& Lo, A. W. (2011). The origin of behavior. Quarterly Journal of Finance, 1(1), 55-108.

Bruguier, A. J., Quartz, S. R., \& Bossaerts, P. (2010). Exploring the nature of trader intuition. Journal of Finance, 65(5), 1703-1723.

Choi, J. J., Laibson, D., Madrian, B. C., \& Metrick, A. (2009). Reinforcement learning and savings behavior. Journal of Finance, 64(6), 2515-2534.

FICO. (2011). Predicting Strategic Default. April, white paper.

Fryman, C., Barberis, N., Camerer, C., Bossaerts, P., \& Rangel, A. (2014). Using neural data to test a theory of investor behavior: an application of realization utility. Journal of Finance, 69(2), 907-946.

Grinblatt, M., \& Keloharju, M. (2009). Sensation seeking, overconfidence, and trading activity. Journal of Finance, 64(2), 549-578.

Guiso, L., Sapienza, P., \& Zingales, L. (2013). The determinants of attitudes towards strategic default on mortgages. Journal of Finance, 68(4), 1473-1515.

Huesing, B., Jancke, L., \& Tag, B. (2006). Impact Assessment of Neuroimaging. Zurich: Hochschulverlag.

James, R. N., \& O’Boyle, M. W. (2014). Charitable estate planning as visualized autobiography: an fMRI study of its neural correlates. Nonprofit and Voluntary Sector Quarterly, 43(2), 355-373.

Jenkinson, M., Bannister, P. R., Brady, J. M., \& Smith, S. M. (2002). Improved optimisation for the robust and accurate linear registration and motion correction of brain images. NeuroImage, 17(2), 825-841.

Kahneman, D., \& Tversky, A. (1979). Prospect theory: an analysis of decisions under risk. Econometrica, 47(2), 313-327.

Logothetis, N. K., Pauls, J., Augath, M., Trinath, T., \& Oeltermann, A. (2001). Neurophysiological investigation of the basis of the fMRI signal. Nature, 412, 150-157.

Markowitz, H. (1952). Portfolio selection. Journal of Finance, 7(1), 77-91.

Ogawa, S., Lee, T. M., Nayak, A. S., \& Glynn, P. (1990). Oxygenation-sensitive contrast in magnetic resonance image of rodent brain at high magnetic fields. Magnetic Resonance Medicine, 14(1), 68-78.

Ogawa, S., Tank, D. W., Menon, R., Ellermann, J. M., Kim, S. G., Merkle, H., \& Ugurbil, K. (1992). Intrinsic signal changes accompanying sensory stimulation: functional brain mapping with magnetic resonance imaging. Proceedings of the National Academy of Sciences, 89, 5951-5955.

Preuschoff, K., Quartz, S. R., \& Bossaerts, P. (2008). Human insula activation reflects risk prediction errors as well as risk. Journal of Neuroscience, 28(1), 2745-2752.

Seiler, M. J., Seiler, V. L., Lane, M. A., \& Harrison, D. M. (2012). Fear, shame, and guilt: economic and behavioral motivations for strategic default. Real Estate Economics, 40(S1), 199-233.

Staw, B. M. (1976). Knee-deep in the Big muddy: a study of escalating commitment to a chosen course of action. Organizational Behavior and Human Performance, 16(1), 27-44.

Veen, V. V., Krug, M. K., Schooler, J. W., \& Carter, C. S. (2009). Neural activity predicts attitude change in cognitive dissonance. Nature Neuroscience, 12(11), 1469-1475. 
White, B. (2010). Underwater and Not walking away: shame, fear, and the social management of the housing crisis. Wake Forest Law Review, 45, 971-1023.

Wilkinson-Ryan, T., \& Hoffman, D. A. (2010). Breech is for suckers. Vanderbilt Law Review, 63(4), 10031045.

Woolrich, M. W., Ripley, B. D., Brady, J. M., \& Smith, S. M. (2001). Temporal autocorrelation in univariate linear modelling of FMRI data. NeuroImage, 14(6), 1370-1386.

Woolrich, M. W., Behrens, T. E., Beckmann, C. F., Jenkinson, M., \& Smith, S. M. (2004). Multi-level linear modelling for FMRI group analysis using Bayesian inference. NeuroImage, 21(4), 1732-1747.

Worsley, K.J. (2001). Statistical Analysis of Activation Images. Ch 14, in Functional MRI: An Introduction to Methods, In P. Jezzard, P.M. Matthews and S.M. Smith (eds) OUP

Wu, C. C., Bossaerts, P., \& Knutson, B. (2011). The affective impact of financial skewness on neural activity and choice. Open Access, 6(2), 1-7.

Zeng, J., Zhang, Q., Chen, C., Yu, R., \& Gong, Q. (2013). An fMRI study on sunk cost effect. Brain Research, $1519(26), 63-70$. 
Copyright of Journal of Real Estate Finance \& Economics is the property of Springer Science $\&$ Business Media B.V. and its content may not be copied or emailed to multiple sites or posted to a listserv without the copyright holder's express written permission. However, users may print, download, or email articles for individual use. 